\title{
Regulation of CFTR Expression and Arginine Vasopressin Activity Are Dependent on Polycystin-1 in Kidney- Derived Cells
}

\author{
Carolina Monteiro de Lemos Barbosaa,d Jackson Souza-Menezes ${ }^{a, b}$ \\ Andressa Godoy Amaralc Luiz Fernando Onuchic ${ }^{c}$ Liudmila Cebotaru $^{\mathrm{e}}$ \\ William B. Guggino ${ }^{d}$ Marcelo M. Morales ${ }^{a}$
}

aLaboratório de Fisiologia Celular e Molecular, Instituto de Biofísica Carlos Chagas Filho, Universidade Federal do Rio de Janeiro, Rio de Janeiro, 'Laboratório Integrado de Ciências Morfofuncionais, Núcleo em Ecologia e Desenvolvimento Sócio-Ambiental, Universidade Federal do Rio de Janeiro, Macaé, RJ, 'Department of Medicine, Division of Molecular Medicine, University of São Paulo School of Medicine, São Paulo, Brazil; dDepartment of Physiology, Johns Hopkins University, Baltimore, MD, eDepartment of Medicine, Johns Hopkins University, Baltimore, MD, USA

\section{Key Words}

CFTR • Kidney • Arginine vasopressin hormone • Polycystin • Autosomal dominant polycystic kidney disease

\begin{abstract}
Background: Autosomal dominant polycystic kidney disease (ADPKD) is characterized by the development of multiple, progressive, fluid-filled renal cysts that distort the renal parenchyma, leading to end-stage renal failure, mainly after the fifth decade of life. ADPKD is caused by a mutation in the PKD1 or PKD2 genes that encode polycystin-1 (PC-1) and polycystin-2 (PC-2), respectively. PC-1 is an important regulator of several signaling pathways and PC-2 is a nonselective calcium channel. The CFTR chloride channel is responsible for driving net fluid secretion into the cysts, promoting cyst growth. Arginine vasopressin hormone (AVP), in turn, is capable of increasing cystic intracellular CAMP, contributing to cell proliferation, transepithelial fluid secretion, and therefore to disease progression. The aim of this study was to assess if AVP can modulate CFTR and whether PC-1 plays a role in this potential modulation. Methods: M1 cells, derived from mouse cortical collecting duct, were used in the current work. The cells were treated with $10^{-7} \mathrm{M}$ AVP hormone and divided into two main groups: transfected cells superexpressing PC-1 (Transf) and cells not transfected (Ctrl). CFTR expression was assessed by immunodetection, CFTR mRNA levels were quantified by quantitative reverse transcription-polymerase chain reaction, and CFTR net ion transport was measured using the Ussing chamber technique. Results: AVP treatment increased the levels

Dr. W.B. Guggino and Dr. M.M. Morales share (equal sharing) the senior authorship

Prof. Marcelo Marcos Morales, M.D., Ph.D. L Laboratory of Cellular and Molecular Physiology, Carlos Chagas Filho Biophysics Institute, Federal University of Rio de Janeiro, Centro de Ciências da Saúde, Avenida Carlos Chagas Filho, s/n, Bloco G-014, Ilha do Fundão, 21941-902, Rio de Janeiro RJ (Brazil)


of CFTR protein and mRNA. CFTR short-circuit currents were also increased. However, when PC-1 was overexpressed in M1 cells, no increase in any of these parameters was detected. Conclusions: CFTR chloride channel expression is increased by AVP in M1 cells and PC-1 is capable of regulating this modulation.

Copyright $@ 2016$ S. Karger AG, Basel

\section{Introduction}

Autosomal dominant polycystic kidney disease (ADPKD) is the most prevalent lifethreatening monogenic disease in the world; its prevalence varies from 1:400 to 1:1000 live births [1-4]. In the United States, it is estimated that around 300,000 to 600,000 individuals are affected [5] by this disease. In addition, it is the primary genetic cause of renal disease and the fourth cause of end-stage renal disease (ESRD), after diabetes, hypertension, and glomerulonephritis [6].

ADPKD is characterized by the formation of multiple fluid-filled cysts that originate from the renal tubules and progressively enlarge and multiply in the parenchyma. Cyst growth occurs as a result of a high cell proliferation rate and fluid secretion into the cysts, leading to distortion of the kidney architecture. By compressing surrounding nephrons and promoting progressive renal inflammation and fibrosis, expansion of the cysts is followed by gradual replacement of the normal parenchyma with cysts and fibrotic tissue. Kidney function declines throughout life such that $50 \%$ of patients reach ESRD by the end of the sixth decade of life [5, 7-9]. Extra-renal manifestations such as cysts in the liver, pancreas, and arachnoid can also occur as well as vascular abnormalities typically represented by intracranial aneurisms $[10,11]$.

ADPKD is caused by loss-of-function mutations in PKD1 or PKD2, genes that encode polycystin-1 (PC-1) and polycystin-2 (PC-2), respectively. In 85\% of cases of ADPKD, the mutations occur in PKD1; the other $15 \%$ of patients present mutations in PKD2 [12,13].

PC-1 is a large integral membrane protein $(>460 \mathrm{kDa})$ with a prominent extracellular amino terminal portion, 11 transmembrane domains, and a short intracellular carboxy terminal tail. PC-1 is thought to be a mechanosensor in renal primary cilia, sensorial organelles that transduce mechanical and chemical extracellular signals into intracellular signaling. The amino terminal leucine-rich domains can bind to collagen, fibronectin, and laminin, promoting cell-matrix interactions. The immunoglobulin-like domains of this portion are responsible for cell-cell interactions. The carboxy terminal portion of PC- 1 can undergo cleavage and migrate to the nucleus and the proteolytic products can regulate gene expression. PC-2 is a smaller integral membrane protein $(110 \mathrm{kDa})$ with six transmembrane domains and intracytosolic N and C termini. PC-1 and PC-2 can interact with each other through their cytosolic carboxy terminal tails. This polycystin complex interacts with other proteins, regulating multiple intracellular signaling pathways critical to renal tubular structure and function during embryonic development and throughout life [14].

Previous studies have shown that mutations in PC-1 and PC-2 can increase cAMP levels, a central regulator of cyst growth. Intracellular cAMP promotes ADPKD cyst cell proliferation and transepithelial fluid secretion, including chloride [15-17]. Furthermore, cAMP agonists stimulate fluid secretion across monolayers of epithelial cells lining ADPKD cysts, as well as the proliferation of these cells [18]. In addition, increased levels of cAMP resulting from activation of the vasopressin (AVP) V2 receptor (V2R) pathway in collecting duct cells contribute to the progression of cystogenesis. Several studies have shown that V2R is hyperactivated and overexpressed in renal cysts of ADPKD animals, suggesting that the cystic cells are more responsive to AVP than normal renal cells [19-22].

Intracellular cAMP levels are increased in different types of cystic animal models [19, $20,23,24]$ and in cultured human ADPKD cystic cells [25]. It is plausible that PC-1 may regulate intracellular levels of cAMP, and its reduced/absent function in ADPKD could lead to increased levels of cAMP and, consequently, to exacerbated transepithelial fluid secretion, cyst formation and enlargement [26], and polycystic kidneys [15].

\section{KARGER}


cAMP-dependent anion secretion to the cyst lumen has been reported to be mediated by the luminal cystic fibrosis transmembrane conductance regulator (CFTR) [27, 28]. This channel has a key role in cyst formation by secreting chloride to the cyst lumen and driving sodium and water secretion to the interior of the cysts [29-32].

AVP hormone and the CFTR chloride channel are important in the pathogenesis of ADPKD as key regulators of cyst expansion. The mechanism underlying this regulation has not been totally elucidated, although the CFTR chloride channel has been shown to contribute to disease progression by driving fluid secretion to the cyst lumen. Therefore, study of the possible modulation of AVP over CFTR and how they are related is fundamental to elucidate the pathophysiology of the disease. The aim of this study was to investigate the possible modulation of CFTR by AVP and the possible regulation of this interaction by PC- 1 .

\section{Materials and Methods}

\section{Cell culture and treatments}

M1 cells (ATCC CRL-2038) originating from mouse cortical collecting ducts were used [33]. The cells were cultivated in Dulbecco's modified essential medium: nutrient mixture F12 (DMEM/F12, Invitrogen, catalog no. 11320-033) with 17.5 mM glucose, supplemented with 10\% fetal bovine serum (FBS), 100 U/ $\mathrm{ml}$ penicillin, and $100 \mu \mathrm{g} / \mathrm{ml}$ streptomycin (GIBCO) at $37^{\circ} \mathrm{C}$ in a $5 \% \mathrm{CO}_{2}$ humidified atmosphere. Before each treatment, the cells were incubated with medium without FBS for $12 \mathrm{~h}$. Hormonal treatment with $10^{-7} \mathrm{M}$ AVP ([ $\left.\mathrm{Arg}^{8}\right]$-vasopressin acetate salt; Sigma, catalog no. V9879) was performed at different time points: 1 , $2,3,4,6,8$ and $24 \mathrm{~h}$. The control group did not receive any hormonal treatment. After each treatment, total RNA or total protein was extracted.

Several drugs were used to increase intracellular cAMP: $100 \mu \mathrm{M}$ 3-isobutyl-1-methylxanthine (IBMX) (catalog no. I5879), $5 \mu \mathrm{M}$ forskolin (catalog no. F6886), and $100 \mu \mathrm{M}$ 8Br-cAMP (catalog no. B5386). $5 \mu \mathrm{M}$ H-89 (catalog no. \# B5386) was used as protein kinase A (PKA) inhibitor. All drugs were purchased from Sigma.

\section{Cell transfection}

M1 cells were grown to 80-90\% confluence in a six-well plate and then transfected with Lipofectamine 2000 (Invitrogen) according to the manufacturer's instructions. Two micrograms of WT-GFP plasmid, which encodes wild-type PKD1 with an N-terminal GFP tag, were used per well (kindly provided by Dr Gregory Germino, Johns Hopkins University, Baltimore, MD, USA). Transfection only with the GFP vector plasmid (1 $\mu \mathrm{g}$ ) (pEGFP-C1, catalog no. 6084-1, BD Biosciences) was used as transfection control. No significant changes in the parameters were observed in cells transfected only with the GFP vector plasmid (data not shown). Different plasmid concentrations were used because PC-1 is a large and difficult-to-express protein. Twentyfour hours after transfection, the cells were treated for an additional $24 \mathrm{~h}$ with $10^{-7} \mathrm{M}$ AVP as described above.

\section{Protein extraction and immunoblotting}

Cells were harvested and lysed with RIPA buffer: $50 \mathrm{mM}$ Tris-HCl, $150 \mathrm{mM} \mathrm{NaCl}, 2 \mathrm{mM}$ EDTA, $5 \mathrm{mM}$ pyrophosphate, $5 \mathrm{mM}$ sodium vanadate, $400 \mu \mathrm{M}$ phenylmethanesulfonylfluoride (PMSF), 0.1\% sodium dodecyl sulfate (SDS), $0.5 \%$ sodium deoxycholate, 1\% Triton X-100, and $1 \times$ complete protease inhibitor cocktail (Roche Applied Science, catalog no. 11697498001). After homogenization by vortexing, the cells were rotated at $4^{\circ} \mathrm{C}$ for $1 \mathrm{~h}$, followed by centrifugation at $13,000 \times g$ at $4^{\circ} \mathrm{C}$ for $20 \mathrm{~min}$. The supernatant was collected and the protein concentration was measured using the BCA protein kit assay (Pierce, catalog no. 23225). After incubation with $2 \times$ Laemmli buffer (Bio-Rad, catalog no. 161-0737) at $42^{\circ} \mathrm{C}$ for $30 \mathrm{~min}, 50 \mu \mathrm{g}$ of each sample was separated by size using a regular SDS-PAGE technique with $4-15 \%$ polyacrylamide gel. After SDS-PAGE, the proteins were electrophoretically transferred to a polyvinylidene fluoride membrane (Millipore, catalog no. IPVH00010) using the Bio-Rad transference apparatus. Nonspecific membrane sites were blocked using 5\% nonfat milk solution for $1 \mathrm{~h}$ at room temperature. Anti-CFTR (1:2000) (University of North Carolina, antibody 217), anti-V2R (1:1000) (Santa Cruz, catalog no. sc-17933), anti-PC-1 (1:10,000) (Santa Cruz, catalog no. SC-130554), and anti-GAPDH (1:10,000) (Santa Cruz, catalog no. sc-365062) 


\section{Cellular Physiology Cell Physiol Biochem 2016;38:28-39

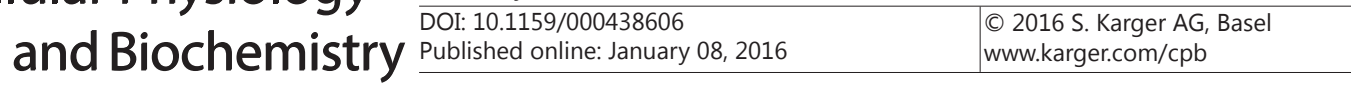 \\ de Lemos Barbosa et al.: CFTR Expression is Dependent of Polycystin-1 in Renal Cells}

primary antibodies were used followed by their respective horseradish peroxidase-conjugated IgG secondary antibody (Pierce). The blots were incubated with Super Signal (Thermo Scientific), whereas the chemiluminescence signal was directly captured by a FujiFilm LAS-3000 plus system with a 3,200,000-pixel cooled CCD camera.

\section{RNA extraction and quantitation}

Total RNA was extracted from M1 cells using an RNeasy Plus mini kit (Qiagen, catalog no. 74134) following the manufacturer's instructions. The RNA concentrations in the samples were determined in a spectrophotometer by absorption at $260 \mathrm{~nm}$. The absorbance ratio $260 \mathrm{~nm} / 280 \mathrm{~nm}$ was used to assess the purity of the samples and ratios close to 2 were considered acceptable for quantitative reverse transcriptionpolymerase chain reaction (qRT-PCR).

\section{Real-time RT-PCR}

Specific primers were designed for mouse CFTR qRT-PCR (156-bp product): sense 5'-TCA GTC CCA TAA AGT GGC CTG GAT-3' and antisense 5'-ACA TGT TAA CTC CTG GAC CTG GCA-3'; mouse GAPDH (115bp product) was used as control: sense $5^{\prime}$-TCA ACA GCA ACT CCC ACT CTT CCA-3' and antisense $5^{\prime}$-ACC CTG TTG CTG TAG CCG TAT-TCA-3'. Reverse transcription was performed using $1 \mu \mathrm{g}$ of total RNA with the Superscript III kit (Invitrogen) and the cDNA produced was submitted to the PCR with SYBR green (Applied Biosystems) in a thermal cycler 7500 (Applied Biosystems). The qRT-PCR protocol included $2 \mathrm{~min}$ at $95^{\circ} \mathrm{C}$, 40 cycles of $15 \mathrm{~s}$ at $95^{\circ} \mathrm{C}$, and $30 \mathrm{~s}$ at $60^{\circ} \mathrm{C}$. The data were analyzed using 7500 software, version 2.0 .5 (Applied Biosystems). Data analysis was performed using the $2^{-\Delta \Lambda C t}$ method.

\section{Measurement of short-circuit currents $\left(I_{s c}\right)$}

Short-circuit current (Isc) measurements were performed in Ussing chambers mounted with Snapwell inserts (Corning, catalog no. 3407). Isc was measured with an EC-825 voltage-current clamp amplifier (World Precision Instruments) in voltage-clamp mode. Cells were cultured to confluence on Snapwell filters until the transepithelial resistance was equal to or higher than $600 \Omega \mathrm{cm} 2$, measured with an electrical resistance system (World Precision Instruments). Cell monolayers were bathed on the basolateral side with Krebs bicarbonate solution containing $115 \mathrm{mM} \mathrm{NaCl}, 25 \mathrm{mM} \mathrm{NaHCO3,} 2.4 \mathrm{mM}$ K2HPO4, $1.2 \mathrm{mM} \mathrm{CaCl} 2,1.2$ $\mathrm{mM} \mathrm{MgCl} 2,0.4 \mathrm{mM} \mathrm{KH} 2 \mathrm{PO} 4$, and $10 \mathrm{mM}$ glucose (pH 7.4). A modified Krebs bicarbonate solution containing 2.0 mM Na-gluconate, $25 \mathrm{mM} \mathrm{NaHCO3,} 2.4 \mathrm{mM} \mathrm{K2HPO4,} 4.0 \mathrm{mM} \mathrm{CaCl} 2,1.2 \mathrm{mM} \mathrm{MgCl} 2,0.4 \mathrm{mM}$ KH2PO4, and $1.6 \mathrm{mM}$ glucose $(\mathrm{pH} 7.4)$ was used on the apical side [34]. The solutions were maintained at $37^{\circ} \mathrm{C}$ and gently bubbled with air so that they could be constantly recirculated. Amiloride $(10 \mu \mathrm{M})$ was added to the apical solution and, after current stabilization, a cAMP cocktail $(100 \mu \mathrm{M}$ 8-Br-cAMP, $100 \mu \mathrm{M}$ IBMX, and $20 \mu \mathrm{M}$ forskolin) was applied to both the apical and basolateral solutions. The cAMP cocktail-stimulated current was blocked by $2 \mu \mathrm{M}$ of CFTR inhibitor-172 (CFTR ${ }_{\text {inh }}-172$ (3-[(3-trifluoromethyl)phenyl]-5-[(4carboxyphenyl)methylene]-2-thioxo-4-thiazolidinone), which is a specific channel blocker for CFTR that leads to rapid, reversible and voltage-independent inhibition. CFTRinh-172 acts as an allosteric inhibitor, targeting the cytoplasmic face of the CFTR protein at its nucleotide-binding domain 1 and maintaining a closed state of the related $\mathrm{Cl}^{-}$conductance $[35,36]$.

\section{Intracellular cAMP measurement}

M1 cells were cultured in 6-well plates and $12 \mathrm{~h}$ before treatment with AVP and IBMX, they were transferred to medium without FBS. Group transfections were performed $24 \mathrm{~h}$ before treatment, as described above. The cells were submitted to $10^{-7} \mathrm{M}$ AVP and $100 \mu \mathrm{M}$ IBMX for $30 \mathrm{~min}$ and washed three times with PBS thereafter, followed by cAMP measurement using a cAMP enzyme immunoassay kit according to the manufacturer's protocol (Sigma, catalog no. CA200).

\section{Statistical analysis}

GraphPad Prism software version 5.01 (GraphPad Software) was used for the statistical analyses. The results are presented as means \pm standard error of the mean. Statistical comparisons among the experimental groups were assessed by one-way ANOVA followed by the Dunnett post-test when required. When only two groups were compared, the unpaired t-test was used. The differences were considered significant when $p<0.05$. 


\section{Results}

The role of $P C$ - 1 in regulating CFTR expression

Cells transfected with PKD1 (Transf) had lower CFTR protein expression compared with cells not overexpressing PC- 1 (Ctrl, $1.00 \pm 0.00$; Transf, $0.54 \pm 0.10 ; n=6, p<0.01$ ). GAPDH was used as internal control. The PC-1 blot demonstrates successful transfection (Fig. 1). The immunoblotting analysis suggests, therefore, that CFTR expression can be regulated by PC-1, because the lack of its expression may contribute to CFTR upregulation.

Regulation of CFTR protein expression by AVP

CFTR protein expression was assessed at different time points after M1 cell treatment with $10^{-7} \mathrm{M}$ AVP hormone. CFTR expression was higher only $24 \mathrm{~h}$ after hormone treatment compared with the control group (Ctrl, $1.00 \pm 0.00 ; 24 \mathrm{~h}, 1.49 \pm 0.11 ; n=6, p<0.05$ ). GAPDH was used as internal control (Fig. 2A). When the cells were transfected with PC-1, no significant changes in CFTR protein expression were observed at any time point after AVP treatment compared with the control group (Ctrl, $1.00 \pm 0.00 ; 1 \mathrm{~h}, 0.88 \pm 0.08 ; 2 \mathrm{~h}, 0.90 \pm$ $0.10 ; 4$ h, $1.04 \pm 0.08 ; 6$ h, $1.24 \pm 0.08 ; 8$ h, $1.21 \pm 0.10 ; 24$ h, $1.14 \pm 0.25 ; n=4, p>0.05$ ) (Fig. 2B).

Fig. 1. CFTR immunodetection in M1 cells. Total protein expression in nontransfected control cells (Ctrl) and PKD1-transfected cells (Transf) overexpressing this protein. ${ }^{*}$ Values are different from the Ctrl group: $p<0.01(n=6)$.
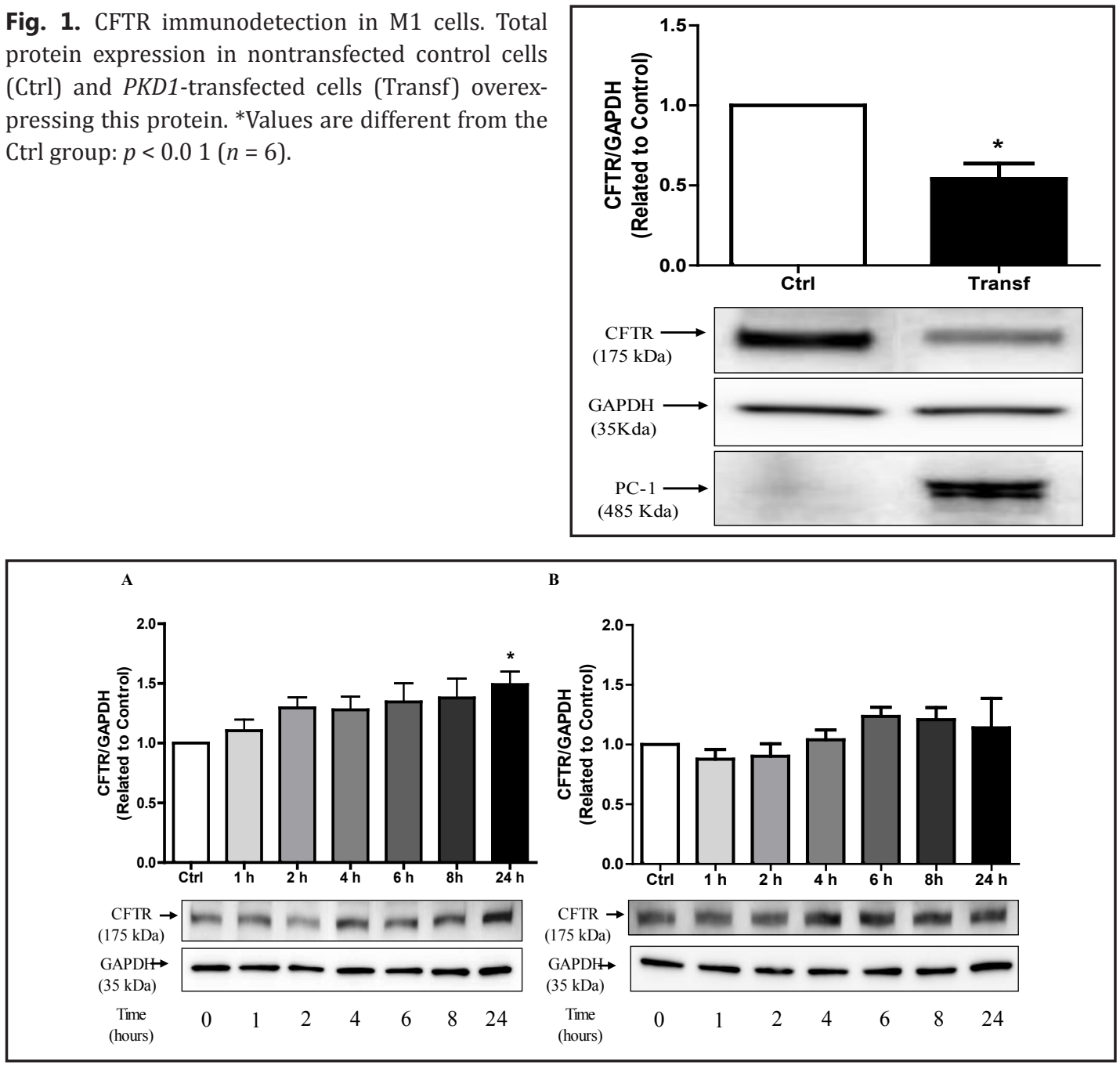

Fig. 2. Western blot for CFTR in M1 cells. Analysis of total protein expression after treatment with AVP $\left(10^{-7} \mathrm{M}\right)$ at different time points. (A) M1 cells not transfected with PC-1. Values are different from point 0 : ${ }^{*} p<0.05(n=6)$. (B) PKD1-transfected M1 cells. In (B), Ctrl cells also express PC-1 ( $\left.p>0.05, n=6\right)$. 


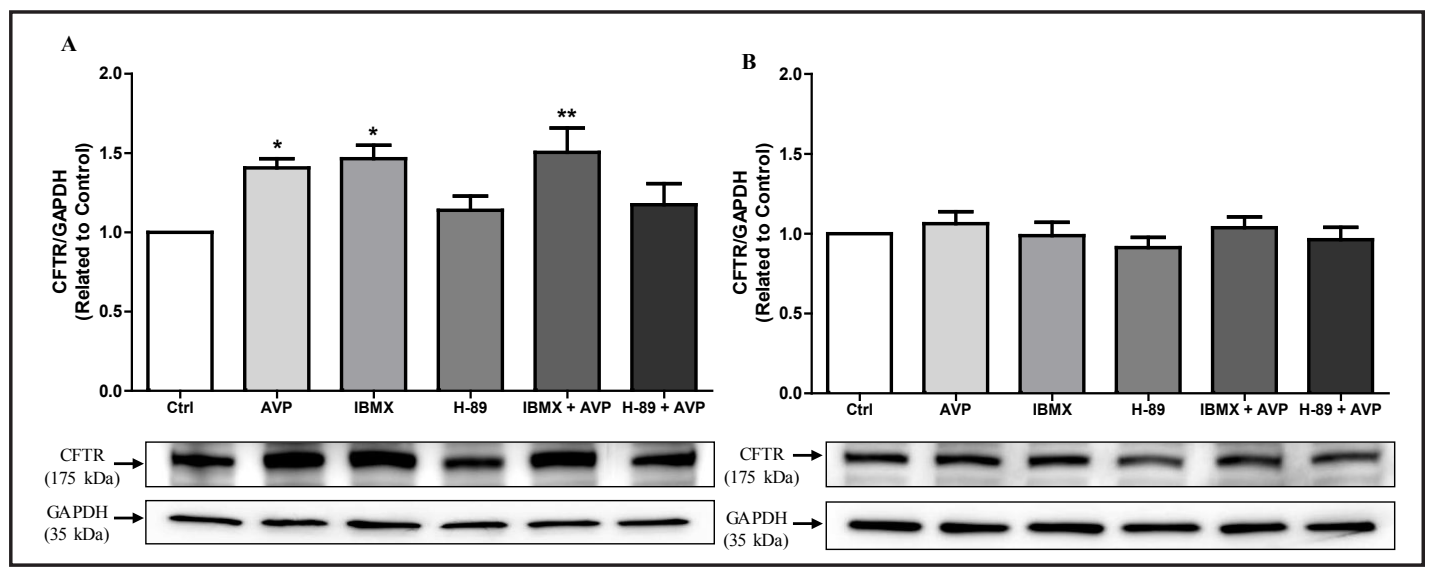

Fig. 3. Western blot for CFTR in M1 cells. Analysis of total protein expression after 24-h treatment with AVP $\left(10^{-7} \mathrm{M}\right)$, IBMX $(100 \mu \mathrm{M})$, and/or H-89 $(75 \mu \mathrm{M})$. (A) M1 cells that do not express PC-1 protein. Values are different from the Ctrl group: ${ }^{*} p<0.05$; ${ }^{* *} p<0.01, n=7$. (B) PKD1-transfected M1 cells. In (B), Ctrl cells also express PC-1 ( $p>0.05, n=7)$.

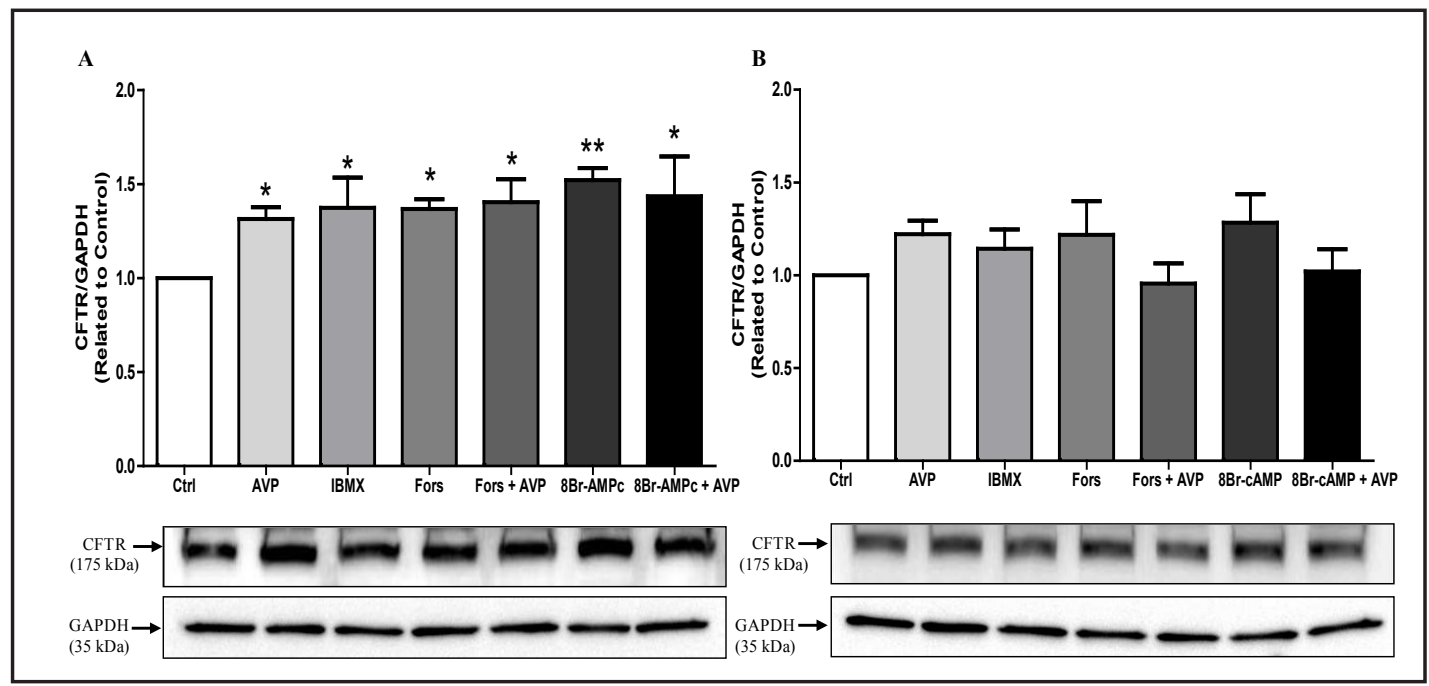

Fig. 4. Western blot for CFTR in M1 cells. Total protein expression analysis after 24-h treatment with AVP $\left(10^{-7} \mathrm{M}\right)$, forskolin $(5 \mu \mathrm{M})$, and/or 8Br-cAMP $(100 \mu \mathrm{M})$. (A) M1 cells that do not express PC-1 protein. Values are different from the Ctrl group: ${ }^{*} p<0.05{ }^{* *} p<0.01, n=6$. (B) PKD1-transfected M1 cells. In (B), Ctrl cells also express PC-1 $(p>0.05, n=6)$.

Impact of increased intracellular cAMP in CFTR protein expression

CFTR protein expression was assessed after different treatments of M1 cells designed to increase intracellular cAMP levels. Such treatments included AVP $\left(10^{-7} \mathrm{M}\right)$, IBMX $(100 \mu \mathrm{M})$, and the PKA inhibitor H-89 $(5 \mu \mathrm{M})$. CFTR protein expression was higher in cells treated with AVP $(1.41 \pm 0.06)$ and IBMX (1.47 \pm 0.08$)$ compared with their control (Ctrl, $1.00 \pm 0.00, n=$ $7, p<0.05)$. Under IBMX + AVP, higher CFTR expression was more prominent $(1.50 \pm 0.15$, $n=7, p<0.01$ ) (Fig. 3A). No significant changes in CFTR protein expression were observed for H-89 + AVP-treated cells $(1.17 \pm 0.13)$ compared with its control group $(1.00 \pm 0.00, n=$ $7, p>0.05$ ) (Fig. 3A). This observation demonstrates that cAMP and PKA may regulate the cell signaling involved in the control of CFTR protein expression. When PKD1 was inserted in this biological system, these differences were no longer significant, indicating that PC-1 was capable of abolishing CFTR modulation ( $n=8, p>0.05$ ) (Fig. 3B).

In other experimental groups, we used AVP $\left(10^{-7} \mathrm{M}\right)$, forskolin (Fors) $(5 \mu \mathrm{M})$, and the cAMP analogue 8Br-cAMP $(100 \mu \mathrm{M})$ in order to increase the intracellular cAMP levels. Higher 
Fig. 5. Western blot for V2R in M1 cells. Analysis of total protein expression in cells that do not express PC-1 (Ctrl) and PKD1-transfected M1 cells (Transf). The PC- 1 blot shows that the transfection was successful. *Values are different from the nontransfected group (Ctrl) $(n=6, p<0.05)$.

expression of CFTR protein was observed in the AVP, IBMX, Fors, Fors + AVP, 8Br-AMPc, and $8 \mathrm{Br}-\mathrm{AMPc}+\mathrm{AVP}$ groups $(1.32 \pm 0.06$ $1.38 \pm 0.16,1.37 \pm 0.05,1.40 \pm 0.12,1.52 \pm$ $0.06,1.44 \pm 0.21$, respectively) compared with the control $(1.00 \pm 0.00, n=6, p<0.05)$ (Fig. 4A). Once again, when PC-1 protein was present, a significant increase in CFTR

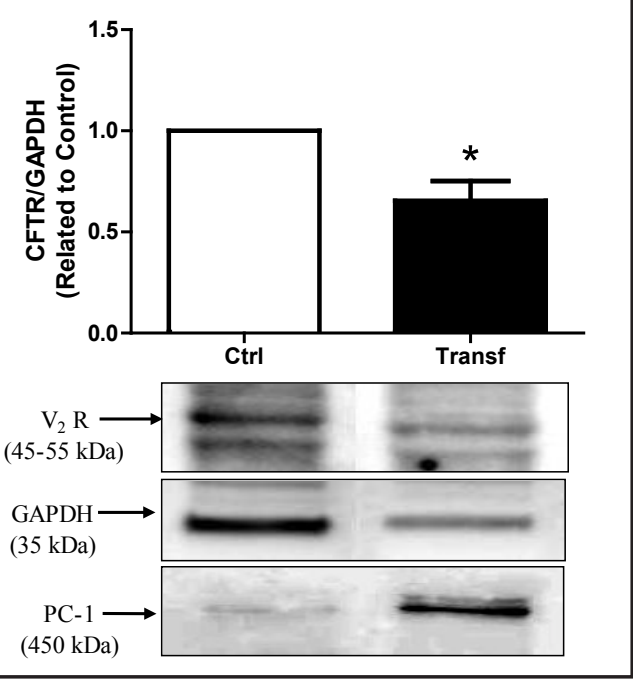
expression could no longer be observed when the cells were stimulated with AVP or in the presence of a higher intracellular concentration of cAMP compared with the control group ( $n=6, p>0.05$ ) (Fig. 4B). These data suggest that PC- 1 is a key protein to prevent CFTR upregulation when intracellular cAMP levels are increased.

The role of $P C-1$ in the regulation of $V 2 R$ protein expression

The expression of V2R was assessed by western blotting in M1 cells with either a higher or basal expression of $\mathrm{PC}-1$ in order to verify whether PC-1 can modulate its expression. A lower level V2R protein expression was observed in PKD1-transfected cells $(0.65 \pm 0.10)$ compared with control cells $(1.00 \pm 0.00 ; n=5, p<0.05)$ (Fig. 5). This finding could explain, at least in part, why CFTR expression was not increased in cells with high PC-1 expression when stimulated with AVP.

CFTR short-circuit currents are modulated by AVP and PC-1

Ussing chambers were used to determine CFTR short-circuit currents ( $\left.I_{\mathrm{sc}}\right)$ in M1 cells previously polarized in transwell filters. When the cells polarize in those filters, they form a layer resembling an epithelium with transepithelial resistance. Thus, short circuit currents can be measured through this layer. Transepithelial conductance was determined in cells expressing PC-1 or not, as well as when submitted to AVP treatment for $24 \mathrm{~h}$.

M1 cells not transfected with $P K D 1$ presented higher transepithelial conductance when treated with AVP $(1.36 \pm 0.20)$ compared with their control (Ctrl, $0.82 \pm 0.12, n=8, p<0.05$ ) (Fig. 6A). On the other hand, PKD1-transfected cells did not show any significant difference in transepithelial conductance after AVP treatment $(0.95 \pm 0.14)$ compared with control cells $(1.12 \pm 0.13, n=6, p>0.05)$ (Fig. 6B). This observation indicates that PC-1 can prevent upregulation in CFTR short-circuit currents stimulated by AVP.

\section{Effects of AVP hormone on CFTR mRNA expression}

CFTR mRNA expression was assessed in M1 cells by qRT-PCR at different time points after treatment with $10^{-7} \mathrm{M}$ AVP hormone. Significant CFTR mRNA upregulation was detected at 8 and $24 \mathrm{~h}$ in cells not transfected with PKD1 after this treatment $(3.50 \pm 0.88$ and 2.74 \pm 0.41 , respectively) compared with the control cells $(1 \pm 0.00, n=4, p<0.05)$. Significant changes in CFTR mRNA expression were not observed $1 \mathrm{~h}, 2 \mathrm{~h}, 4 \mathrm{~h}$, and $6 \mathrm{~h}$ after treatment with $10^{-7}$ M AVP $(1$ h, $0.86 \pm 0.13 ; 2$ h, $1.18 \pm 0.21 ; 4$ h, $1.39 \pm 0.32 ; 6$ h, $1.31 \pm 0.11, n=4$, $p>0.05$ ) (Fig. 7A). When the cells were transfected with PKD1, however, significant changes in CFTR mRNA expression were not found at all time points evaluated after treatment with $10^{-7}$ M AVP (Ctrl, $1 \pm 0.00 ; 1$ h, $1.19 \pm 0.22 ; 2$ h, $1.95 \pm 0.58 ; 4$ h, $2.55 \pm 0.99 ; 6$ h, $2.56 \pm 0.53$, $n=4 ; 8$ h, $1.39 \pm 0.37 ; 24$ h, $2.32 \pm 0.35 ; n=4, p>0.05$ ) compared with the control group (Fig. 7B). 
A

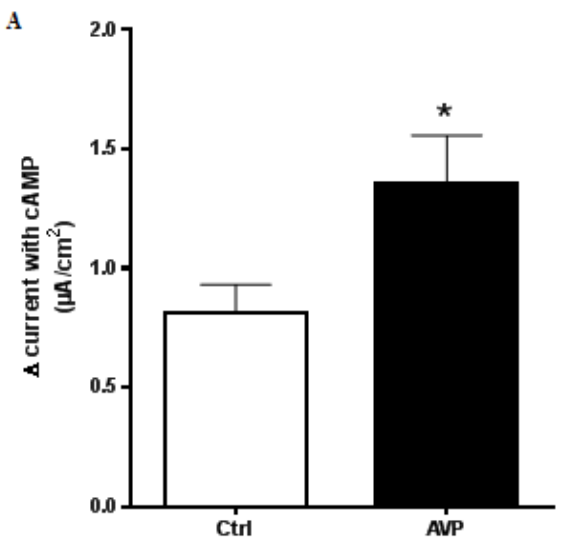

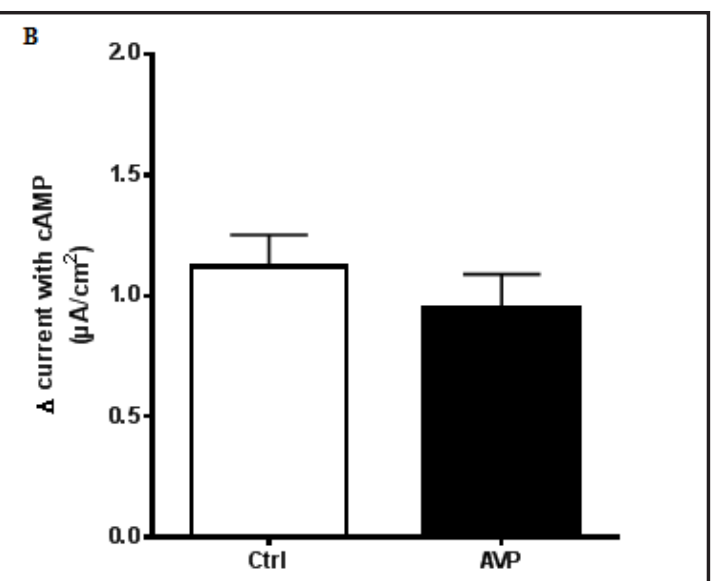

Fig. 6. Changes in CFTR short-circuit chloride currents $\left(\mathrm{I}_{\mathrm{sc}}\right)$ in $\mathrm{M} 1$ cells measured after the current response to cAMP cocktail reached steady-state levels. (A) M1 cells that do not express PC-1 protein. Values are different from the Ctrl group: ${ }^{*} p<0.05$. (B) PKD1-transfected M1 cells. In (B), Ctrl cells also express PC-1.

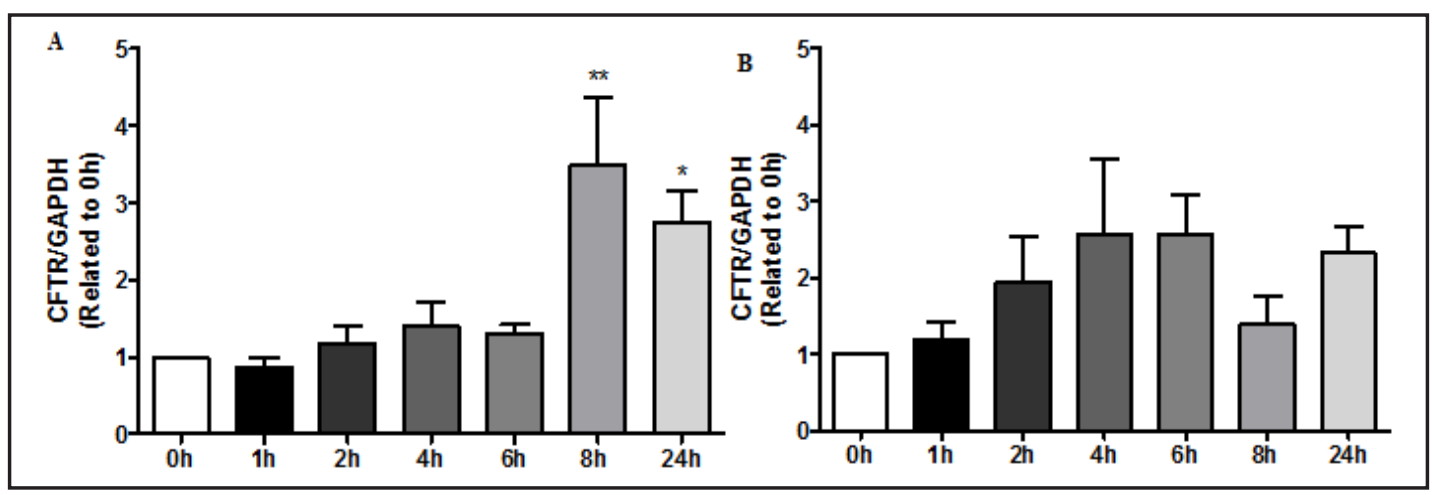

Fig. 7. $q R T-P C R$ for CFTR in M1 cells. Analysis of mRNA expression after treatment with AVP $\left(10^{-7} \mathrm{M}\right)$ at different time points. (A) M1 cells that do not overexpress PC-1 protein. *Values are different from the point 0 $(p<0.05)$ and for ${ }^{* *} p<0.01$. (B) PKD1-transfected M1 cells.

\section{$P C-1$ is involved in the regulation of intracellular cAMP}

The intracellular concentration of cAMP was assessed in PKD1-transfected and nontransfected cells by enzymatic immunoassay. Cells treated with AVP $\left(10^{-7} \mathrm{M}\right)$ and IBMX $(100 \mu \mathrm{M})$ presented a significant increase in cAMP levels $(1.65 \pm 0.10$ and $3.22 \pm$ 0.85 , respectively) compared with the control group (0.95 $\pm 0.05, n=5-8, p<0.05)$. PKD1transfected M1 cells did not show significant change in cAMP intracellular content when treated with $10^{-7} \mathrm{M}$ AVP $(0.66 \pm 0.08)$. Transfected cells treated with $100 \mu \mathrm{M}$ IBMX, however, showed higher levels of intracellular cAMP $(2.58 \pm 0.72)$ compared with the transfected control group (Ctrl, $0.97 \pm 0.21, n=6, p<0.05$ ) (Fig. 8).

\section{Discussion}

Cyst formation in ADPKD is caused by mutations in either PKD1 or PKD2 arising from the renal tubular segments. These cysts increase in number and get filled with fluid over time, compressing the surrounding nephrons and eventually leading to renal failure [37]. The channel responsible for driving the epithelial net secretion inward to the cyst is the CFTR chloride channel, which is therefore a determinant for cyst enlargement and disease progression. In this study, we have demonstrated that, in the presence of PC-1, the CFTR expression decreased 50\% in mouse cortical collecting duct cells (M1 cells), suggesting the control but not abolishment of CFTR conductance by PC-1 in the distal part of the nephron 
Fig. 8. cAMP quantification by immunoassay in M1 cells treated for 30 min with $10^{-7} \mathrm{M}$ AVP or $100 \mu \mathrm{M}$ IBMX. Values are significantly different: ${ }^{*} p<0.05$ or $* * p<0.01$.

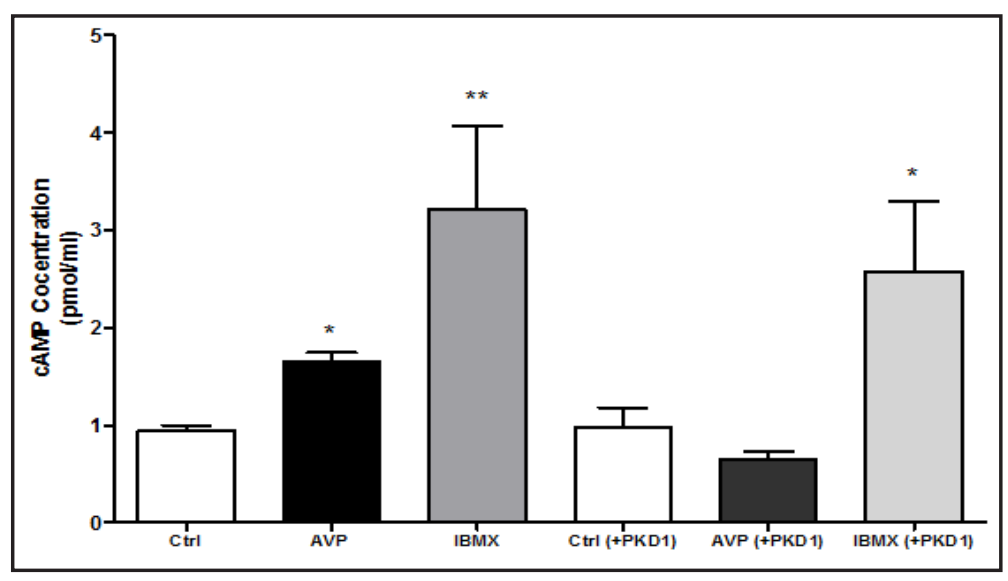

(Fig. 1). Second hits represented by somatic mutations in the previously normal allele are thought to trigger cystogenesis in ADPKD, although other mechanisms have been shown to lead to cystogenesis under particular circumstances [38]. Accumulation of second hits could justify cystic transformation in mice with a heterozygous background. Haploinsufficiency seems to be important in this disease, because Pkd1- and Pkd2-haploinsufficient mice present increased cellular proliferation and interstitial fibrosis [39, 40]. Moreover, Pkd1haploinsufficient mice display increased susceptibility to renal ischemia/reperfusion compared with wild-type controls and develop microcysts after such an insult, a finding not observed in wild-types [41]. Accordingly, PC-1 levels are important in as much as they reduce the rate of cell proliferation and induce resistance to programmed cell death in renal cells, allowing the constitution and maintenance of the tubular phenotype [42].

Physiologically, CFTR is responsible for cAMP-dependent chloride efflux across the apical membranes of collecting ducts $[43,44]$. The secretion of chloride in this distal part of the nephron is thought to finely regulate extracellular fluid volume and composition and maintain urine formation during the cessation of glomerular filtration [45, 46]. Cellular mechanisms for chloride secretion in this segment are regulated by circulating hormones like AVP, a hormone that has been shown to stimulate chloride secretion through cAMPdependent PKA phosphorylation and activation of CFTR chloride channels $[47,48]$.

AVP hormone has an important role in the aggravation of ADPKD by increasing intracellular cAMP and thereby stimulating cystic epithelial cell proliferation and chloride transepithelial secretion inward to the cyst, a process that leads to cyst growth. cAMPdependent proliferation is mediated by PKA and B-Raf, which stimulates MEK/ERK to upregulate the genes involved in cell proliferation [49]. In addition, opening of CFTR depends on cAMP phosphorylation [50]. In the present study, treatment of M1 distal tubule-derived cells with AVP increased CFTR protein and mRNA expression after $24 \mathrm{~h}$, a stimulus that was abolished by the presence of PC-1 (Fig. 2A and 2B; Fig. 7A and 7B) and these results suggest that PKD1 functions as a physiological modulator of AVP renal response, a fact that could be relevant because CFTR is a modulator of other ion conductances and the control of its expression and function could avoid exacerbation of the renal response to hormonal stimulation in as the form of dehydration. In addition, these data suggest that AVP can modulate cyst progression through CFTR. This may be driven by an AVP-mediated increase in CFTR expression, leading to fluid secretion and cyst enlargement. PC-1 overexpression was capable of interfering in this modulation, demonstrating that PC-1 could minimize the deleterious effect of AVP [19, 23, 39, 51].

Increased intracellular levels of cAMP promote cyst growth, an increase in kidney volume, and ADPKD progression [52, 53]. It is well documented that when PC-1 is mutated, as in ADPKD, the concentration of cAMP is abnormally high [15]. In this study, the stimulation of intracellular cAMP in M1 cells by IBMX, forskolin, and 8Br-cAMP led to a significant increase in CFTR protein expression. In the presence of PC-1, however, this modulation was abolished. PKA also seems to play an important role in the regulation of CFTR expression. 
Cells treated with a PKA inhibitor (H-89), associated or not with AVP, did not show an increase in expression of this channel (Fig. 3A and 3B, Fig. 4A and 4B). The lack of PC-1 in M1 cells led not only to an increase in CFTR protein expression but also to an increase in CFTR transepithelial conductance.

When AVP binds to V2R, it triggers a signaling cascade that results in an increase in cAMP levels. This receptor seems to have an important role in the physiopathology of ADPKD given the hyperactivation of V2R observed in cystic epithelial cells [19, 20, 23-25, 54]. Studies demonstrate that V2R is overexpressed in the kidneys of PKD animal models, suggesting that renal cells affected by ADPKD are more responsive to AVP. Moreover, V2R antagonists are capable of inhibiting cystogenesis in ADPKD rat and mouse animal models [19-22]. The mechanisms underlying this inhibition are not fully elucidated. In the present work, V2R protein expression was shown to be decreased in M1 cells overexpressing PC-1, suggesting that PC-1 participates in the modulation of its expression.

The observed upregulation of CFTR protein and mRNA in M1 cells stimulated by AVP was accompanied by increases in CFTR transepithelial currents assessed by CFTR shortcircuit currents measured using an Ussing chamber system. In line with our previous results, the stimulation was abolished in the presence of PC-1 overexpression (Fig. 6A and 6B).

Our data support the concept that PC-1 can modulate/decrease the deleterious effect of AVP on ADPKD-affected kidneys. Our findings demonstrate that AVP regulates CFTR function and expression and that this modulation can be modified by PC-1. Our results strongly suggest, therefore, interaction among AVP, CFTR, and PC-1 in ADPKD pathogenesis.

\section{Acknowledgments}

The authors would like to express their gratitude to Mrs Karina Pereira Gomes and Mr Andre Benedito da Silva for technical support. This study was supported by NIH grant DK032753, Centers of Excellence Program (PRONEX-FAPERJ), Brazilian Council for Scientific and Technological Development (MCT/CNPq), Carlos Chagas Filho Rio de Janeiro State Research Supporting Foundation (FAPERJ), Coordination for the Improvement of Higher Level Personnel (CAPES).

\section{Disclosure Statement}

The authors have no competing interests to declare.

\section{References}

1 Davies F, Coles GA, Harper PS, Williams AJ, Evans C, Cochlin D: Polycystic kidney disease re-evaluated: a population-based study. Q J Med 1991;79:477-485.

2 De Almeida E, Sousa A, Pires C, Aniceto J, Barros S, Prata MM: Prevalence of autosomal- dominant polycystic kidney disease in Alentejo, Portugal. Kidney Int 2001;59:2374.

3 Iglesias CG, Torres VE, Offord KP, Holley KE, Beard CM, Kurland LT: Epidemiology of adult polycystic kidney disease, Olmsted County, Minnesota: 1935-1980. Am J Kidney Dis 1983;2:630-639.

4 Simon P, Le Goff JY, Ang KS, Charasse C, Le Cacheux P, Cam G: [Epidemiologic data, clinical and prognostic features of autosomal dominant polycystic kidney disease in a French region]. Nephrologie 1996;17:123130 (in Fench).

5 Grantham JJ: Autosomal dominant polycystic kidney disease. N Engl J Med 2008;359:1477-14785.

6 Collins AJ, Foley RN, Chavers B, Gilbertson D, Herzog C, Ishani A, Johansen K, Kasiske BL, Kutner N, Liu J, St Peter W, Guo H, Hu Y, Kats A, Li S, Li S,Maloney J, Roberts T, Skeans M, Snyder J, Solid C, Thompson B, Weinhandl E, Xiong H, Yusuf A, Zaun D, Arko C, Chen SC, Daniels F, Ebben J, Frazier E,Johnson R, Sheets D, Wang X, Forrest B, Berrini D, Constantini E, Everson S, Eggers P, Agodoa L: US Renal Data System 2013 Annual Data Report. Am J Kidney Dis 2014;63:A7. doi:10.1053/j.ajkd.2013.11.001 


\section{Cellular Physiology Cell Physiol Biochem 2016;38:28-39 \begin{tabular}{l|l} 
and Biochemistry & $\begin{array}{l}\text { DOI: 10.1159/000438606 } \\
\text { Published online: January 08, 2016 }\end{array}$ \\
\hline
\end{tabular}}

7 Mochizuki T, Tsuchiya K, Nitta K. Autosomal dominant polycystic kidney disease: recent advances in pathogenesis and potential therapies. Clin Exp Nephrol 2013;17:317-326.

8 Torres VE, Harris PC: Autosomal dominant polycystic kidney disease: the last 3 years. Kidney Int 2009;76:149-68.

9 Terryn S, Ho A, Beauwens R, Devuyst O: Fluid transport and cystogenesis in autosomal dominant polycystic kidney disease. Biochim Biophys Acta 2011;1812:1314-1321.

10 Torres VE, Grantham JJ: Cystic diseases of the kidney; in Brenner B (ed): The Kidney. Philadelphia, Saunders Elsevier, 2008, pp 1428-162.

11 Luciano RL, Dahl NK: Extra-renal manifestations of autosomal dominant polycystic kidney disease (ADPKD): considerations for routine screening and management. Nephrol Dial Transplant 2014;29:247254.

12 Wüthrich RP, Serra AL, Kistler AD: Autosomal dominant polycystic kidney disease: new treatment options and how to test their efficacy. Kidney Blood Press Res 2009;32:380-387.

13 Chapman AB: Autosomal dominant polycystic kidney disease: time for a change? J Am Soc Nephrol. 2007;18:1399-1407.

14 Van Adelsberg J, Chamberlain S, D’Agati V: Polycystin expression is temporally and spatially regulated during renal development. Am J Physiol 1997;272: F602-609.

15 Belibi F, Reif G, Wallace DP, Yamaguchi T, Olsen L, Li H, Helmkamp GM Jr, Grantham JJ. Cyclic AMP promotes growth and secretion in human polycystic. Kidney Int 2004;66:964-973.

16 Mangoo-Karim R, Uchic ME, Grant M, Shumate WA, Calvet JP, Park CH, Grantham JJ: Renal epithelial fluid secretion and cyst growth: the role of cyclic AMP. Fed Am Soc Exp Biol 1989;3:2629-2632.

17 Houslay M, Milligan G: Tailoring cAMP-signalling responses through isoform multiplicity. Trends Biochem Sci 1997;22:217-224.

18 Ahrabi AK, Terryn S, Valenti G, Caron N, Serradeil-Le Gal C, Raufaste D, Nielsen S, Horie S, Verbavatz JM, Devuyst 0: PKD1 haploinsufficiency causes a syndrome of inappropriate antidiuresis in mice. J Am Soc Nephrol 2007;18:1740-1753.

19 Gattone VH, Wang X, Harris PC, Torres VE: Inhibition of renal cystic disease development and progression by a vasopressin V2 receptor antagonist. Nat Med 2003;9:1323-1326.

20 Torres VE, Wang X, Qian Q Somlo S, Harris PC, Gattone VH: Effective treatment of an orthologous model of autosomal dominant polycystic kidney disease. Nat Med 2004;10:363-364.

21 Nagao S, Nishii K, Katsuyama M, Kurahashi H, Marunouchi T, Takahashi H, Wallace DP: Increased water intake decreases progression of polycystic kidney disease in the PCK rat. J Am Soc Nephrol 2006;17:22202227.

22 Nagao S, Nishii K, Yoshihara D, Kurahashi H, Nagaoka K, Yamashita T, Takahashi H, Yamaguchi T, Calvet JP, Wallace DP: Calcium channel inhibition accelerates polycystic kidney disease progression in the Cy/+ rat. Kidney Int 2008;73:269-277.

23 Smith LA, Bukanov NO, Husson H, Russo RJ, Barry TC, Taylor AL, Beier DR, Ibraghimov-Beskrovnaya O: Development of polycystic kidney disease in juvenile cystic kidney mice: insights into pathogenesis, ciliary abnormalities, and common features with human disease. J Am Soc Nephrol 2006;17:2821-2831.

24 Yamaguchi T, Nagao S, Kasahara M, Takahashi H, Grantham JJ: Renal accumulation and excretion of cyclic adenosine monophosphate in a murine model of slowly progressive polycystic kidney disease. Am J Kidney Dis 1997;30:703-709.

25 Pinto CS, Reif GA, Nivens E, White C, Wallace DP. Calmodulin-sensitive adenylyl cyclases mediate AVPdependent cAMP production and Cl- secretion by human autosomal dominant polycystic kidney cells. Am J Physiol Renal Physiol 2012;303:F1412-1424.

26 Grantham JJ: Mechanisms of progression in autosomal dominant polycystic kidney disease. Kidney Int Suppl 1997;63:S93-97.

27 Brill SR, Ross KE, Davidow CJ, Ye M, Grantham JJ, Caplan MJ: Immunolocalization of ion transport proteins in human autosomal dominant polycystic kidney epithelial cells. Proc Natl Acad Sci U S A 1996;93:1020610211.

28 Hanaoka K, Devuyst O, Schwiebert EM, Wilson PD, Guggino WB: A role for CFTR in human autosomal dominant polycystic kidney disease. Am J Physiol 1996;270:C389-C999.

29 Chang EB, Bookstein C, Vaandrager A, DeJonge HR, Buse J, Musch MW: Cystic fibrosis transmembrane regulator mRNA expression relative to ion-nutrient transport in spontaneously differentiating human intestinal CaCo-2 epithelial cells. J Lab Clin Med 1991;118:377-381.

30 Morales MM, Falkenstein D, Lopes AG. The cystic fibrosis transmembrane regulator (CFTR) in the kidney. An Acad Bras Cienc 2000;72:399-406.

31 Souza-Menezes J, Morales MM: CFTR structure and function: is there a role in the kidney? Biophys Rev 2009;1:3-12. 


\section{Cellular Physiology Cell Physiol Biochem 2016;38:28-39 and Biochemistry

32 Souza-Menezes J, Feltran, GS, Morales MM: CFTR and TNR-CFTR expression and function in the kidney. Biophys Rev 2014;6:227-236.

33 Stoos BA, Náray-Fejes-Tóth A, Carretero OA, Ito S, Fejes-Tóth G: Characterization of a mouse cortical collecting duct cell line. Kidney Int 1991;39:1168-1175.

34 Clarke LL: A guide to Ussing chamber studies of mouse intestine. Am J Physiol Gastrointest Liver Physiol 2009;296:G1151-1166.

35 Ma T, Thiagarajah JR, Yang H, Sonawane ND, Folli C, Galietta LJV, Verkman AS: Thiazolidinone CFTR inhibitor identified by high-throughput screening blocks cholera toxin-induced intestinal fluid secretion. J Clin Invest 2002;110:1651-1658.

36 Caci E, Caputo A, Hinzpeter A, Arous N, Fanen P, Sonawane N, Verkman AS, Ravazzolo R, Zegarra-Moran O, Galietta LJV: Evidence for direct CFTR inhibition by CFTR(inh)-172 based on Arg347 mutagenesis. Biochem J 2008;413:135-142.

37 Grantham JJ, Mulamalla S, Swenson-Fields KI: Why kidneys fail in autosomal dominant polycystic kidney disease. Nat Rev Nephrol 2011;7:556-566.

38 Ong ACM, Harris PC: Molecular pathogenesis of ADPKD: the polycystin complex gets complex. Kidney Int 2005;67:1234-1247.

39 Parker E, Newby LJ, Sharpe CC, Rossetti S, Streets AJ, Harris PC, O'Hare MJ, Ong AC: Hyperproliferation of PKD1 cystic cells is induced by insulin-like growth factor-1 activation of the Ras/Raf signalling system. Kidney Int 2007;72:157-165.

40 Chang MY, Parker E, Ibrahim S, Shortland JR, Nahas M El, Haylor JL, Ong AC: Haploinsufficiency of Pkd2 is associated with increased tubular cell proliferation and interstitial fibrosis in two murine Pkd2 models. Nephrol Dial Transplant 2006;21:2078-2084.

41 Bastos AP, Piontek K, Silva AM, Martini D, Menezes LF, Fonseca JM, Fonseca II, Germino GG, Onuchic LF: Pkd1 haploinsufficiency increases renal damage and induces microcyst formation following ischemia/ reperfusion. J Am Soc Nephrol 2009;20:2389-2402.

42 Boletta A, Qian F, Onuchic LF, Bhunia AK, Phakdeekitcharoen B, Hanaoka K, Guggino W, Monaco L, Germino GG: Polycystin-1, the gene product of PKD1, induces resistance to apoptosis and spontaneous tubulogenesis in MDCK cells. Mol Cell 2000;6:1267-1273.

43 Wallace DP, Rome LA, Sullivan LP, Grantham JJ: cAMP-dependent fluid secretion in rat inner medullary collecting ducts. Am J Physiol Renal Physiol 2001;280: F1019-F1029.

44 Wallace DP, Christensen M, Reif G, Belibi F, Thrasher B, Duke H, Grantham, JJ: Electrolyte and fluid secretion by cultured human inner medullary collecting duct cells. Am J Physiol Renal Physiol 2002;283: F13371150.

45 Grantham JJ, Wallace DP: Return of the secretory kidney. Am J Physiol Renal Physiol 2002;282:F1-9.

46 Rajagopal M, Wallace DP: Chloride secretion by renal collecting ducts. Curr Opin Nephrol Hypertens 2015;24:444-449.

47 Montesano R, Ghzili H, Carrozzino F, Rossier, BC, Féraille E: cAMP-dependent chloride secretion mediates tubule enlargement and cyst formation by cultured mammalian collecting duct cells. Am J Physiol Renal Physiol 2009;296:F446-457.

48 Sullivan LP, Wallace DP, Grantham JJ: Chloride and Fluid Secretion in Polycystic Disease. J Am Soc Nephrol 1998;9:903-916.

49 Yamaguchi T, Nagao S, Wallace DP, Belibi FA, Cowley BD, Pelling JC, Grantham JJ: Cyclic AMP activates B-Raf and ERK in cyst epithelial cells from autosomal-dominant polycystic kidneys. Kidney Int 2003;63:19831994.

50 Anderson MP, Berger HA, Rich DP, Gregory RJ, Smith AE, Welsh MJ: Nucleoside triphosphates are required to open the CFTR chloride channel. Cell 1991;67:775-784.

51 Lu W, Fan X, Basora N, Babakhanlou H, Law T, Rifai N, Harris PC, Perez-Atayde AR, Rennke HG, Zhou J: Late onset of renal and hepatic cysts in Pkd1-targeted heterozygotes. Nat Genet 1999;21:160-161.

52 Wallace DP: Cyclic AMP-mediated cyst expansion. Biochim Biophys Acta 2011;1812:1291-1300.

53 Parnell SC, Magenheimer BS, Maser RL, Rankin CA, Smine A, Okamoto T, Calvet JP: The polycystic kidney disease-1 protein, polycystin-1, binds and activates heterotrimeric G-proteins in vitro. Biochem Biophys Res Commun 1998;251:625-631.

54 Heggö O: A microdissection study of cystic disease of the kidneys in adults. J Pathol Bacteriol 1966;91:311315. 